\title{
Pneumomediastino, pneumotórax e enfisema subcutâneo em cão com pneumopatia e infecção pelo vírus da cinomose: relato de caso
}

\author{
[Pneumomediastinum, pneumothorax and subcutaneous emphysema in a dog with pneumopathy and infection by the \\ canine distemper virus: case report] \\ G.U. Eguchi ${ }^{1}$, D.R. Oliveira $^{1}$, P.A.T. Andreussi ${ }^{2}$, V.J.B. Terra ${ }^{2}$, M.I.P. Palumbo ${ }^{2 *}$ \\ ${ }^{1}$ Aluno de pós-graduação - FAMEZ - Universidade Federal de Mato Grosso do Sul - Campo Grande, MS \\ ${ }^{2}$ Universidade Federal de Mato Grosso do Sul - Campo Grande, MS
}

\begin{abstract}
RESUMO
Relata-se um caso de pneumomediastino, pneumotórax e enfisema subcutâneo em um cão com pneumopatia associada à cinomose. As queixas principais eram tosse, secreção nasal purulenta, apatia e enfisema subcutâneo em face, região cervical e torácica. $\mathrm{O}$ exame radiográfico evidenciou pneumomediastino, pneumotórax e broncopneumopatia grave com áreas de consolidação pulmonar. Teste rápido imunocromatográfico para detecção de antígeno da cinomose foi positivo e houve melhora dos sinais respiratórios com antibioticoterapia, porém o quadro evoluiu para alterações neurológicas. De acordo com a revisão de literatura realizada, não há casos semelhantes relatados.
\end{abstract}

Palavras-chave: dispneia, doenças transmissíveis, radiografia torácica

\begin{abstract}
A case of pneumomediastinum, pneumothorax and subcutaneous emphysema in a dog with pneumopathy associated to distemper is reported. The main complaints were cough, purulent nasal discharge, lethargy and subcutaneous emphysema in the face, neck, and chest area. Radiographic examination showed pneumomediastinum, pneumothorax, and severe bronchopneumopathy with areas of pulmonary consolidation. Rapid test for canine distemper antigen detection was positive. After the antibiotic therapy there was an improvement of respiratory signs; however, the patient developed neurological symptomatology. As far as the author's knowledge by literature review carried out, there are no similar cases reported.
\end{abstract}

Keywords: dyspnea, communicable diseases, thoracic radiograph

\section{INTRODUÇÃO}

Pneumomediastino caracteriza-se pelo acúmulo de ar dentro do espaço mediastinal e indica processos patológicos (Samii, 2008). O mediastino cranial possui continuidade com os planos fasciais cervicais, e o acúmulo de ar nessa região, por dissecação tecidual, leva a enfisema subcutâneo cervical e torácico (Macklin, 1939). Pneumotórax também pode ocorrer pelo aumento de pressão e distensão das pleuras mediastinais (Samii, 2008).
Em relação às causas mais frequentes de pneumomediastino em cães e gatos, traumas torácicos, intubação endotraqueal com ventilação positiva, feridas penetrantes, corpo estranho e pneumonias com ruptura alveolar estão entre as principais etiologias (Maes et al., 2011; Thomas e Syring, 2013). Também são descritos casos de origem desconhecida, classificados como pneumomediastino espontâneo, porém de menor incidência e possivelmente com fator racial predisponente (Thomas e Syring, 2013; Agut et al., 2015).

Recebido em 21 de fevereiro de 2017

Aceito em 22 de novembro de 2017

*Autor para correspondência (corresponding author)

E-mail: mariana.palumbo@ufms.br 
Radiografias torácicas usualmente são suficientes para diagnóstico, no entanto tomografia computadorizada ou ressonância magnética podem ser necessárias (Samii, 2008). O tratamento depende da etiologia do pneumomediastino, podendo haver necessidade de intervenção cirúrgica exploratória para pesquisa de possíveis rupturas traqueais, esofágicas e de trato respiratório inferior (Kellagher e White, 1987; Stephens et al., 2002).

A cinomose canina é uma doença de etiologia viral, com alta morbidade e mortalidade associada à infecção de cães não vacinados (Greene e Appel, 2006). Posteriormente à infecção por via aérea, a replicação viral inicial ocorre em linfonodos regionais cervicais e torácicos e, após viremia, dissemina-se por vários tecidos, evoluindo na fase final da doença para lesões em sistema nervoso central (Greene e Appel, 2006).

Tosse, espirros, dispneia e secreção nasal são sinais clínicos comuns de pacientes com cinomose e estão associados com replicação tecidual do vírus, podendo haver agravamento por infecções bacterianas secundárias, em consequência da imunossupressão (Greene e Appel, 2006). A evolução das alterações pulmonares pode ser grave, podendo ocorrer pneumonias intersticiais com evolução para óbito antes do desenvolvimento de sinais clínicos gastroentéricos ou neurológicos (Pandher et al., 2006).

O diagnóstico de cinomose para pacientes em viremia e com sinais clínicos sistêmicos (secreções oculares e nasais, tosse, espirro, hiperqueratose de focinho e coxins plantares, ceratoconjuntivite seca) é usualmente fácil, com disponibilidade de teste rápido por imunocromatografia para pesquisa de antígeno ou visualização de inclusões de Lentz em esfregaços de sangue periférico (Greene e Appel, 2006).

Apesar de infecções pelo vírus da cinomose serem bastante comuns no Brasil e com potencial de provocar pneumopatias, não existem registros de casos que tenham evoluído para pneumomediastino ou enfisema subcutâneo. Considerando-se a falta de descrição dessas alterações em medicina veterinária, o objetivo deste trabalho é relatar um caso de paciente canino acometido pelo vírus da cinomose, com apresentação clínica incomum de pneumomediastino, pneumotórax e enfisema subcutâneo, associado à pneumopatia grave.

\section{CASUÍSTICA}

Foi atendido, no Hospital Veterinário da Faculdade de Medicina Veterinária e Zootecnia da Universidade Federal de Mato Grosso do Sul, um canino, macho, Teckel, 10 anos de idade, com queixa principal de tosse seca havia 72 horas, secreção nasal serosa, apatia, hiporexia e secreção ocular purulenta havia cinco dias, porém com melhora desse sinal clínico após início de administração tópica de pomada oftálmica veterinária à base de gentamicina e hidrocortisona. $\mathrm{O}$ cão não tinha acesso livre à rua nem histórico de trauma. Vacinação de reforço polivalente havia sido feita há dois anos.

Durante exame físico, foi observada dispneia expiratória, posição ortopneica e aumento de volume difuso em face e região cervical ventral, estendendo-se até região torácica ventral (Fig. 1A e B), sinal clínico não observado previamente pelo proprietário, portanto, sem informação de tempo de evolução. Havia crepitação à palpação da pele (enfisema subcutâneo) em toda região de aumento de volume. A ausculta pulmonar identificou discreto abafamento em foco pulmonar cranioventral esquerdo. Não havia sinais de nocicepção à palpação em toda região de coluna vertebral cervical, torácica e nas costelas. Não havia secreção ocular purulenta como relatado pelo proprietário, mas ceratite ulcerativa em olho direito (teste de fluoresceína positivo). Também foi observada secreção nasal serosa. Demais parâmetros físicos estavam dentro dos valores de referência para a espécie. 


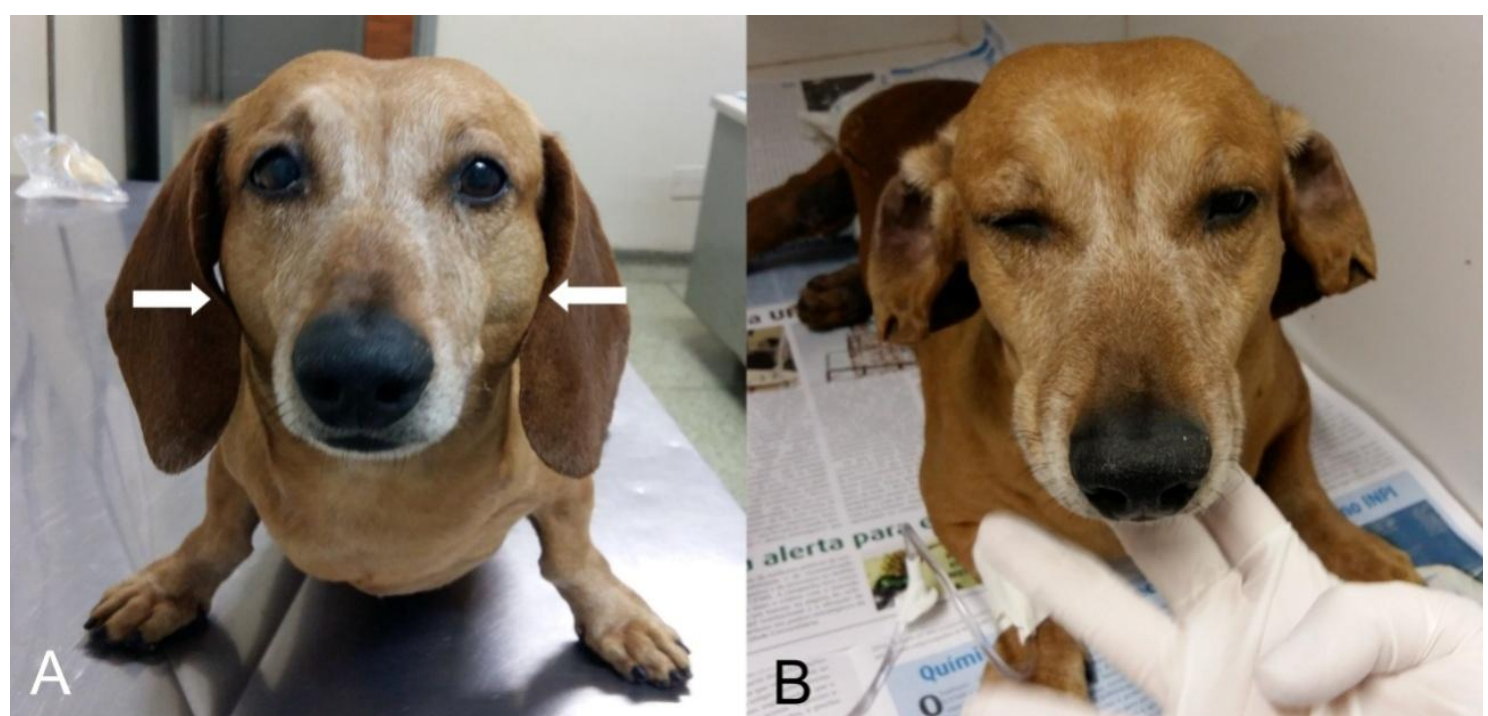

Figura 1. A) Paciente canino em posição ortopneica apresentando enfisema subcutâneo cervical ventral; notar o aumento de volume em face e região cervical estendendo-se próximo à região mandibular (setas). B) Mesmo paciente após 24 horas de evolução; notar a redução visível do aumento de volume em comparação ao dia anterior.

Foi realizado teste rápido para cinomose $(\mathrm{Ag}$ SensPERT ${ }^{\circledR}$ - Vencofarma $\left.{ }^{\circledR}\right)$ de amostra de conjuntiva ocular e secreção nasal, com resultado positivo. Hemograma revelou leucocitose $19.200 \mathrm{~mm}^{3}$ (referência 6.000 a $17.000 \mathrm{~mm}^{3}$ ) por neutrofilia $17.664 \mathrm{~mm}^{3}$ (referência 3.000 a $11.500 \mathrm{~mm}^{3}$ ) e linfopenia $768 \mathrm{~mm}^{3}$ (referência 1.000 a $4.800 \mathrm{~mm}^{3}$ ). Bioquímica sérica identificou hipoproteinemia $4,75 \mathrm{~g} / \mathrm{dL}$ (referência 5,4 a $7,1 \mathrm{~g} / \mathrm{dL}$ ), hipoalbuminemia $2,2 \mathrm{~g} / \mathrm{dL}$ (referência 2,6 a 3,3g/dL), hipoglobulinemia 2,55g/dL (referência 2,7 a 4,4g/dL), alanina aminotransferase e creatinina séricas abaixo dos valores de referência 16,7UI/L (referência 21 a $86 \mathrm{UI} / \mathrm{L}$ ) e $0,3 \mathrm{mg} / \mathrm{dL}$ (referência 0,5 a $1,5 \mathrm{mg} / \mathrm{dL}$ ), respectivamente. Houve crescimento bacteriano (Staphylococcus sp.) observado em amostras de conjuntiva ocular e de secreção nasal.

Radiografias torácicas nas projeções ventrodorsal e laterolateral direita revelaram a presença de pneumomediastino cranial, pneumotórax e enfisema subcutâneo cervical e torácico, além de evidenciarem campos pulmonares apresentando padrão misto, predominantemente alveolar, discretamente brônquico e intersticial, localizados bilateralmente, com aumento de radiopacidade delimitando parte do lobo caudal direito e porção do lobo cranial esquerdo, sugestivos de broncopneumopatia e áreas de consolidação pulmonar (Fig. 2A e B).
Conduta terapêutica incluiu antibioticoterapia (amoxicilina $22 \mathrm{mg} / \mathrm{kg} /$ por via oral $/$ a cada 12 horas), n-acetilcisteína $(3 \mathrm{mg} / \mathrm{kg} /$ por via oral $/ \mathrm{a}$ cada 12 horas), complexo vitamínico (Organoneuro Cerebral®/ uma drágea/ por via oral/ a cada 24 horas), aplicação de soro contra cinomose (Soroglobulin ${ }^{\circledR} \quad 2 \mathrm{ml} / \mathrm{kg} / \mathrm{via}$ subcutânea/dose única), substituição de pomada oftálmica por colírio de tobramicina (uma gota em ambos os olhos/a cada oito horas), diclofenaco sódico (uma gota em ambos os olhos/a cada 12 horas) e lubrificante ocular (Systane ${ }^{\circledR}$ ) (uma gota em ambos os olhos/a cada duas horas).

Após 24 horas, já foi observada redução do aumento de volume cervical, redução da crepitação em tecido subcutâneo e melhora da dispneia observada durante a consulta inicial. Durante 72 horas consecutivas, o paciente retornou diariamente para tratamento ambulatorial de suporte com fluidoterapia, cuidados de enfermagem e observação para possível intervenção emergencial. Após esse período, o paciente foi liberado para continuidade do tratamento em casa.

Passados 10 dias, o paciente retornou para reavaliação física e radiografia torácica (Fig. 2C e D). $\mathrm{O}$ animal não apresentava mais enfisema subcutâneo e dispneia, porém começou 


\section{Eguchi et al.}

a apresentar sinais clínicos neurológicos característicos de síndrome vestibular central, os quais continuaram evoluindo, tendo o proprietário optado pela eutanásia.

Durante a necropsia, a avaliação macroscópica não identificou ruptura em traqueia e esôfago cervical ou torácico, ou em via aérea inferior. A histopatologia pulmonar identificou congestão discreta, difusa, com edema alveolar multifocal. As alterações observadas no sistema nervoso central foram de encefalite linfoplasmocítica necrosante, multifocal, associada a corpúsculos de inclusão intranuclear em astrócitos.

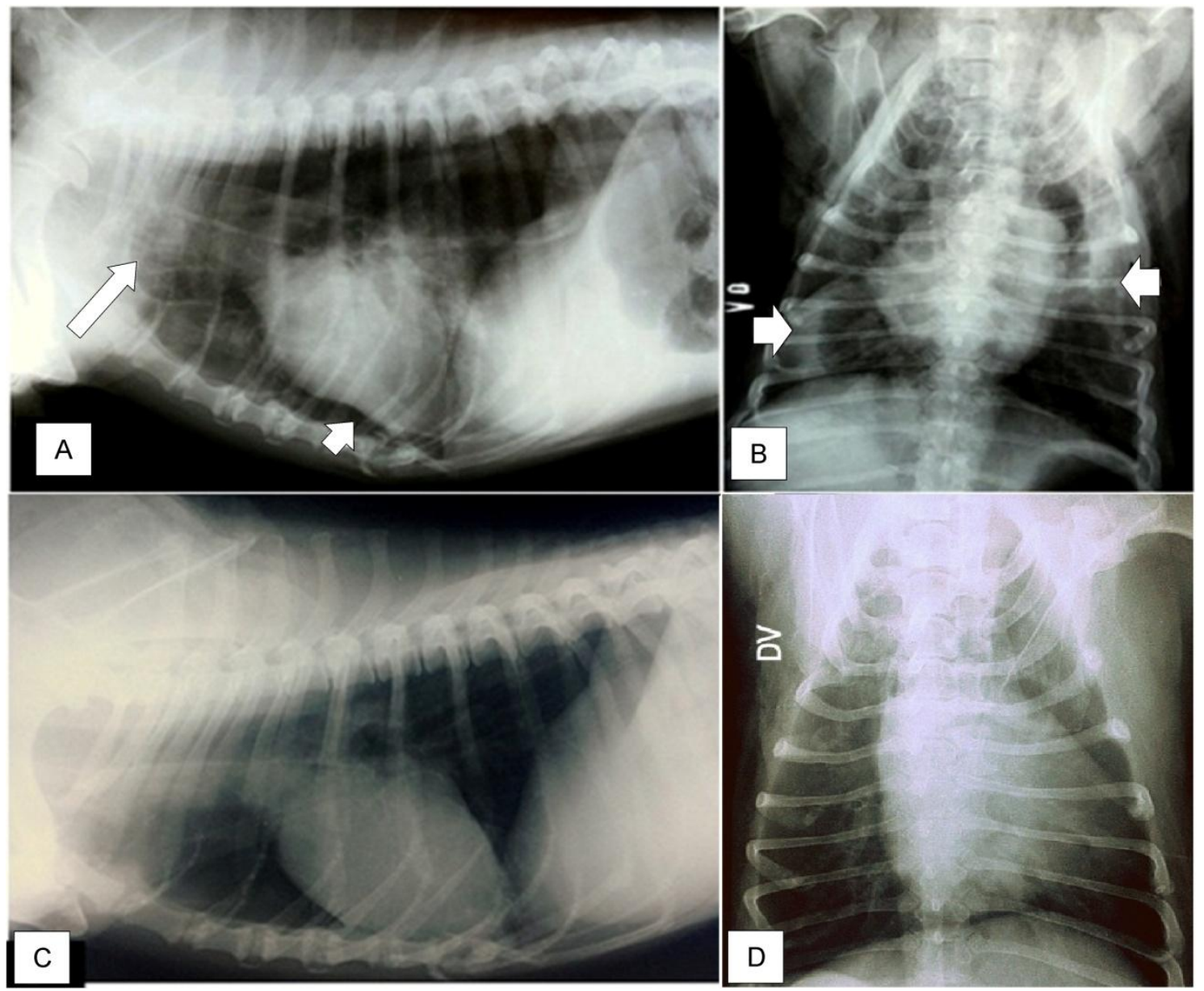

Figura 2. Radiografias torácicas de paciente canino nas projeções laterolateral direita e ventrodorsal em dia zero (A e B) e laterolateral e dorsoventral 10 dias após (C e D). A) Mediastino evidente devido à presença de ar (pneumomediastino) (seta maior) e espaço pleural delimitado por ar, diminuindo contato cardioesternal (pneumotórax) (seta menor). B) Notar campos pulmonares com padrão misto e áreas de consolidação pulmonar (setas largas). C) Notar ausência das evidências anteriores de pneumotórax. D) Notar melhora em relação ao exame anterior, com discreta área alveolar e bronquial.

\section{DISCUSSÃO E CONCLUSÕES}

As causas mais comuns de pneumomediastino e enfisema subcutâneo em cães e gatos são traumáticas, secundárias à contusão pulmonar e ruptura traqueal, de forma que os dados de anamnese usualmente são suficientes para determinar sua origem (Kellagher e White, 1987;
Bauer e Currie, 1988; Thomas e Syring, 2013). Entre outras causas já conhecidas, há relatos de pneumonia bacteriana por Staphylococcus sp. em humanos (Finnie et al., 1995), pneumonia necrotizante secundária a herpes vírus felino-1 (Maes et al., 2011) e doença pulmonar intersticial fibrosante em cães (Agut et al., 2015). Usualmente, não são identificadas as causas de 
pneumopatias que acabam provocando o pneumomediastino, sendo este classificado como pneumomediastino espontâneo (Järvinen et al., 1995; Stephens et al., 2002). De acordo com a revisão de literatura realizada, este é o primeiro caso relatado de pneumomediastino em um cão com pneumopatia secundária ao vírus da cinomose canina.

Foi excluída a possibilidade de pneumomediastino traumático, pois não havia histórico de qualquer possibilidade de contusões, firmado tanto por informação de ambiente (vivia dentro de casa), sem acesso livre à rua e sem contactantes caninos diretos, além de minuciosa inspeção em exames físico e necroscópico, que não identificaram qualquer sinal de perfuração ou escoriação.

Apesar do histórico de vacinação do animal com produtos polivalentes em um período de dois anos prévios, o diagnóstico de cinomose não é incomum, pois, embora imunidade prolongada de até três anos para o caso de cinomose seja relatada, a falha na resposta vacinal pode ocorrer devido a diversos fatores, como resposta imunológica ineficiente inerente ao indivíduo, má conservação do produto e contato com cepas virais de maior virulência, podendo ocorrer evolução clássica dos sinais clínicos da doença mesmo em animais vacinados (Greene e Appel, 2006).

O teste imunocromatográfico rápido com detecção de antígeno positivo foi considerado suficiente para diagnóstico de cinomose. Lesões pulmonares por esse vírus já são bem documentadas. Elas causam sinais clínicos de sistema respiratório na maioria dos animais infectados e provocam desde sinais brandos a pneumonias intersticiais com lesões inflamatórias de alvéolos, bem como dispneia severa, podendo haver, ainda, agravamento por infecções bacterianas secundárias (Greene e Appel, 2006; Pandher et al., 2006).

Pneumopatias podem culminar em ruptura alveolar levando ao escape de ar que transita até o interstício pulmonar através do leito vascular e posteriormente extravasa no mediastino, evento chamado de efeito Macklin (Macklin, 1939). A pneumopatia de padrão alveolar, identificada radiograficamente, pode ter sido a causa da tosse descrita pelo proprietário, e o aumento de pressão intratorácica provocado pelas crises de tosse, associado às lesões primárias pulmonares, pode ter levado à ruptura alveolar, originando o extravasamento de ar para o mediastino.

Enfisema subcutâneo é um sinal clínico comum consequente ao pneumomediastino, relatado tanto para pacientes veterinários quanto para humanos (Maes et al., 2011). Isso ocorre pela comunicação que o mediastino possui com os planos fasciais cervicais, podendo o acúmulo de ar mediastinal disseminar-se pela região cervical por dissecação tecidual que provoca em sua tentativa de escape (Macklin, 1939). A evolução do quadro clínico de redução do enfisema subcutâneo e de melhora da dispneia reforçou o diagnóstico presuntivo de lesão atraumática, pois uma ruptura traqueal, mais dificilmente diagnosticada radiograficamente que uma lesão pulmonar, evoluiria com piora ou manutenção dos sinais clínicos.

O prognóstico do pneumomediastino parece estar relacionado à gravidade da doença pulmonar envolvida, tendo casos de resolução espontânea sem nenhum tratamento clínico ou cirúrgico específico ou evolução para óbito em casos de pneumopatias mais severas (Stephens et al., 2002; Maes et al., 2011; Agut et al., 2015). Acredita-se que o tratamento de suporte terapêutico com antibiótico de amplo espectro por período prolongado (14 dias) pode ter sido responsável pela melhora tanto clínica quanto de achado histopatológico de lesões brandas em tecido pulmonar.

A evolução do caso descrito para melhora do quadro clínico em 72 horas, sem intervenção cirúrgica exploratória, descreve uma alternativa mais conservadora para pacientes diagnosticados com enfisema subcutâneo por pneumomediastino consequente de doença pulmonar intersticial infecciosa. Até o momento, por conhecimento dos autores, não há relato semelhante tendo o vírus da cinomose como responsável. 


\section{REFERÊNCIAS}

AGUT, A.; TALAVERA, J.; BUENDIA, A. $e t$ al. Imaging diagnosis - spontaneous pneumomediastinum secondary to primary pulmonary pathology in a Dalmatian dog. Vet. Radiol. Ultrasound, v.56, p.E54-E57, 2015.

BAUER, M.S.; CURRIE, J. Generalized subcutaneous emphysema in a dog. Can. Vet. J., v.29, p.836-837, 1988.

FINNIE, I.A.; JACK, C.I.A.; McKAY, J.S. Pneumomediastinum and subcutaneous emphysema complicating staphylococcal pneumonia. Ulster Med. J., v.64, p.105-107, 1995.

GREENE, C.E.; APPEL, M.J. Canine distemper. In: GREENE, C.E. (Ed.). Infectious Diseases of the Dog and Cat. 3.ed. Philadelphia: Elsevier, 2006. p.27-41.

JÄRVINEN, A.K.; SAARIO, E.; ANDRESEN, E. et al. Lung injury leading to respiratory distress syndrome in young Dalmatian dogs. $J$. Vet. Intern. Med., v.9, p.162-168, 1995.

KELLAGHER, R.E.B.; WHITE, R.A.S. Tracheal rupture in a dog. J. Small Anim. Pract., v.28, p.29-38, 1987.
MACKLIN, C.C. Transport of air along sheaths of pulmonic blood vessels from alveoli to mediastinum: clinical implications. Arch. Intern. Med., v.64, p.913, 1939.

MAES, S.; GOETHEM, B.V.; SAUNDERS, J. et al. Pneumomediastinum and subcutaneous emphysema in a cat associated with necrotizing bronchopneumonia caused by feline herpesvirus1. Can. Vet. J., v.52, p.1119-1122, 2011.

PANDHER, K.; PODELL, B.; GOULD, D.H. et $a l$. Interstitial pneumonia in neonatal canine pups with evidence of canine distemper virus infection. J. Vet. Diagn. Invest., v.18, p.201-220, 2006.

SAMII, V.F. Diagnóstico por imagem dos distúrbios respiratórios. In: BIRCHARD, S. J.; SHERDING, R.G. (Eds.). Manual Saunders de Clínica de Pequenos Animais. São Paulo: Roca, 2008. p.1663-1676.

STEPHENS, J.A.; PARNELL, N.K.; CLARKE, $\mathrm{K}$. et al. Subcutaneous emphysema, pneumomediastinum, and pulmonary emphysema in a young schipperke. J. Am. Anim. Hosp. Assoc., v.38, p.121-124, 2002.

THOMAS, E.K.; SYRING, R.S. Pneumomediastinum in cats: 45 cases (20002010). J. Vet. Emerg. Crit. Care, v.23, p.429435, 2013. 